\title{
Correction to: Thinking inside the box: new ways of considering energy consumption in a multi-user agency-constrained environment
}

\author{
Ksenia Chmutina (D) Andrew Dainty • \\ Robert Schmidt III • Elli Nikolaidou • \\ Eirini Mantesi $\cdot$ Yang Yu $\cdot$ Malcolm Cook
}

Published online: 4 January 2022

(C) Springer Nature B.V. 2022

\section{Correction to: Energy Efficienct https://doi.org/10.1007/s12053-021-10003-y}

The original version of the article unfortunately does not contain an appropriate acknowledgement.

The authors would like to acknowledge that this research has been funded by UKRI EPSRC grant reference EP/P033911/1.

The original article has been corrected.

Publisher's note Springer Nature remains neutral with regard to jurisdictional claims in published maps and institutional affiliations.

The original article can be found online at https://doi.org/ 10.1007/s12053-021-10003-y.

K. Chmutina $(\bowtie) \cdot$ A. Dainty $\cdot$ R. Schmidt III

E. Mantesi · Y. Yu · M. Cook

School of Architecture, Building and Civil Engineering,

Loughborough University, Loughborough LE11 3TU, UK

e-mail:k.chmutina@lboro.ac.uk

E. Nikolaidou

Department of Architecture \& Civil Engineering,

University of Bath, Bath BA2 7AY, UK 